\title{
The General Visceral Efferent Component of the Eighth Cranial Nerve ${ }^{1,2}$
}

\author{
MURIEL D. ROSS \\ Department of Anatomy, University of Michigan, Ann Arbor, Michigan
}

\begin{abstract}
Study of the brain stem, stato-acoustic nerve, and inner ear of the mouse by a cholinesterase technique has disclosed that the acetylcholinesterase-positive centrifugal fibers to the inner ear are part of a general visceral efferent system which supplies fibers to the facial, vestibular and cochlear nerves. This system largely corresponds in its central course to that of the bundle of fibers which has been called "olivocochlear," but its cells of origin do not appear to lie in the superior olivary complex. Instead, the preganglionic cells of origin are chiefly organized into four nuclei: one medial to the genu of the facial nerve; one lateral to the genu; the superior salivatory nucleus; and a small nucleus lying within the borders of the lateral vestibular nucleus. The fibers to the inner ear synapse, perhaps completely, on postganglionic cells located along their peripheral courses. Additionally, orthosympathetic acetylcholinesterasepositive fibers are present in the cochlear nerve; they arrive via the anterior inferior cerebellar artery. Postganglionic fibers supply not only vascular walls and secretory epithelium in the inner ear but also (1) contact the somata of some acetylcholinesterase-positive, bipolar cochlear neurons and (2) ramify among, or terminate upon, distal, acetylcholinesterase-positive processes of some sensory neurons at the foramina nervosa. These findings indicate that, on morphological grounds, autonomic nerve activity may influence auditory input at the periphery.
\end{abstract}

The original purpose of this investigation was to determine whether or not observable changes occurred in the olivo-cochlear bundle prior to, concurrent with, or following the loss of the organ of Corti and spiral ganglion cells in a species of mice which becomes progressively deaf with age (Ross, '65a,b). It was hoped that the study would yield information concerning a possible neurotrophic influence of the efferent system upon the receptor organ. A cholinesterase technique was used to selectively stain in their entirety the neurons whose axons comprise the bundle. Sections of skulls with brains and inner ears in situ were prepared so that the origin, course and termination of the bundle could be determined in serial sections. Normal and abnormal mice were used so that valid comparisons could be made. It became apparent as the study progressed that, in the mouse, the acetylcholinesterase-positive fiber bundle which supplies the inner ear does not arise chiefly from the superior olivary complex. With this finding, attention was turned toward a complete investigation of the centrifugal bundle to the inner ear as it occurs in the normal mouse.

\section{MATERIALS AND METHODS}

Thirty-three normal mice were prepared for microscopic examination. The mice were of Peromyscus maniculatus bairdi stock obtained from the Laboratory of Mammalian Genetics at The University of Michigan. Twenty-six normal animals between 17 and 26 days postnatal age were beheaded; the fur, snout, and lower jaw were removed; the remaining portions of the skull with brain in situ were frozen on dry ice without prior decalcification, mounted, and sectioned at $14 \mu$ in a cryostat at $-18^{\circ} \mathrm{C}$. Sections were mounted on coverslips, kept frozen until all sectioning was completed, and then prepared by Holmstedt's ('57) modification of Koelle's technique for cholinesterases except that development with ammonium sulfide was carried out. The sections were washed briefly three times in distilled water, held in a $10 \%$ ammonium sulfide solution for 30 seconds, washed again briefly in distilled watex, and then placed on slides with glycerin jelly as the mounting medium. Different incubation periods and $\mathrm{pH}$ values were used on individual series, with one hour and fifteen minutes incubation in solutions at $\mathrm{pH} 6.4$ proving optimal for most tissues prepared.

Four complete series were counterstained with cresyl violet following treatment with ammonium sulfide. The sections were washed briefly in distilled water, fixed in buffered $10 \%$ formalin for

${ }_{1}$ Supported by Deafness Research Foundation; University of Michigan H. H. Rackham Fac. Res. Proj. 787; and U.S.P.H.S. NB-07306-01.

2 Presented in part at the annual meeting of the American Association of Anatomists, New Orleans, La., April, 1968. 
30 minutes, rinsed again, then immersed for three minutes in a $0.25 \%$ solution of cresyl violet adjusted to $\mathrm{pH} 3.5$ and heated to $56^{\circ} \mathrm{C}$. Sections were differentiated in three changes of $95 \%$ alcohol, for a total of 15 minutes, then dehydrated and mounted on slides with permount.

In three series, pretreatment of some sections with eserine in concentrations ranging between $10^{-4}$ and $10^{-8}$ molar was carried out. In one series, some sections were pretreated with $10^{-6} \mathrm{mo}$ lar concentration of DFP.

The brains, only, of four additional normal mice over three months of age were treated identically in order to determine whether or not differences in staining quality due to age exist. No such differences were noted between these animals and those 19 to 21 days old. Animals of 17 days postnatal age generally yielded better stained tissues when longer incubation times were used (one and one-half to two hours).

Recently, pretreatment with EDTA of skulls with brains and inner ears in situ of animals over three months of age followed by the histochemical procedure outlined above has been fairly successful in yielding typical patterns of distribution of acetyl and butyrylcholinesterase. The enzymes are diminished quantitatively, however, as the reactions are never so intense as those in the fresh material. These results, obtained in three specimens, are included in this report. The method followed was essentially that given by Balogh and Nomura ('64), except that the $\mathrm{pH}$ of the incubating medium used in the histochemical procedure was lowered to $\mathrm{pH}$ 6.4. The authors recommend a $\mathrm{pH}$ of 7.4 which, in the case of the mouse, results in considerable diffusion artifact of the enzymes. This artifact frequently masks the cells of origin of the acetylcholinesterase-positive fibers centrally and leads to staining of all the vestibular and cochlear neurons peripherally. Use of a lower $\mathrm{pH}$ eliminates some of this artifact.

\section{DESCRIPTION OF FINDINGS}

Superior olivary complex. None of the typical fusiform cells of the superior olive, accessory superior olive, or nucleus trapezoidalis medialis stain positively for acetylcholinesterase with the incubation periods or $\mathrm{pH}$ used (figs. 1,2). A few multipolar cells possessing cytoplasmic acetylcholinesterase are sometimes scattered in the regions of infolding of the superior olivary nucleus or along its dorsolateral border. These cells correspond to the marginal and retro-olivary neurons described by Cajal ('09), but not to the neurons described by Poliak ('26) or Rasmussen ('46) as retroolivary.

There are acetylcholinesterase-positive neurons in the lateral preolivary nucleus (nucleus trapezoidalis lateralis), differing morphologically and in strength of enzymatic reaction through the caudorostral ex- tent of the nucleus. The closely grouped and highly acetylcholinesterase-positive cells along the caudoventral border of the superior olivary nucleus are of mediumsize, plump, multiangular, and have eccentric nuclei. Prominent dorsal processes extend from these cells into the rostral part of the facial nucleus (fig. 2). This small clump of neurons merges anteriorly with and is replaced by a group of scattered, moderately acetylcholinesterase-positive, fusiform neurons with eccentric nuclei. These latter cells have long dorsal, medial and lateral processes, but it could not be determined which was the axon. The dorsal process occasionally extends through the superior olive into the tegmentum; the medial, into the region of the medial preolivary nucleus; and the lateral, into the lateral lemniscus. These fusiform cells are loosely continuous at the lateral border of the superior olive with more closely grouped multipolar neurons of less enzymatic reactivity which possess a central nucleus. Rostrally, this group of cells merges with the ventral nucleus of the lateral lemniscus.

There are exceedingly few neurons in the medial preolivary nucleus (nucleus trapezoidalis ventralis). Those present are similar morphologically and histochemically to the acetylcholinesterase-positive, fusiform neurons of the lateral preolivary nucleus.

Although positively stained fibers of fine diameter course vertically through the field, dorsal to the superior olivary complex, none of them can be traced to an origin in any portion of the latter complex in the present material.

Visceral efferent pathway. The cells of origin of the acetylcholinesterase-positive pathway referred to as the "olivo-cochlear bundle" are distributed along the central course of their centrifugal bundle and are loosely organized into three nuclear groups: (1) a nucleus medial to the genu of the facial nerve; (2) a nucleus closely related to the ventrolateral border of the genu of the facial nerve; and (3) the superior salivatory nucleus. Additionally, a fourth small nucleus of autonomic cells located ventrally in the lateral vestibular nucleus is linked by fibers to the "olivocochlear bundle." 
Medial to the genu of the facial nerve two types of neurons can be distinguished both morphologically and histochemically (fig. 3). Only the most dorsomedial neurons appear to be typical preganglionic cells and to contribute to the visceral system described here. The more ventral appear to be reticular cells. They have two long processes, one of which extends ventralward toward the superior olivary complex and the other rostomedialward toward the midline (fig. 3 ).

The nucleus ventrolateral to the genu of the facial nerve consists of small, multipolar and acetylcholinesterase-positive neurons. Distribution of the enzyme is heavier in the cell body than in the axon (figs. 1, 3 ). Some of these cells send their axons ventralward with the distal root of the facial nerve, while either collaterals of the same cells or axons of others are sent into the laterally coursing efferent bundle.

The superior salivatory nucleus is a small cluster of multipolar, acetylcholinesterase-positive cells situated dorsolaterally in the medulla, directly in the path of the laterally coursing efferent bundle (fig. 1). This nucleus is located inferior to the lateral vestibular nucleus and medial to the nucleus of fasciculus solitarius. The superior salivatory nucleus is connected with the larger inferior salivatory nucleus by a slender column of cells and fibers.

These three nuclei are linked together by the laterally coursing efferent fibers to which their cells give rise, and to the contralateral nuclei by a decussation of some of the fibers at the most rostral limits of the facial genu (fig. 4). Whether or not all of the nuclei contribute fibers to the contralateral efferent bundle cannot be determined in the available material. Only the medially situated group of neurons can be shown with certainty to send some axons across the midline.

The bundle thus formed of ipsilateral and contralateral fibers has been called "olivo-cochlear." It splits into smaller fascicles and then recombines in its course across the dorsolateral tegmentum to the superior salivatory nucleus. In this region four main fascicles diverge from the bundle, only one of which ultimately supplies the cochlea. This branch, the largest, will be considered in detail below. A second smaller, but prominent, fascicle loops dorsolateralward toward the small nucleus of autonomic cells in the lateral vestibular nucleus; the later course of this fascicle is also considered below. The remaining two fascicles distribute with nervus intermedius; one of them leaves the ventral aspect of the superior salivatory nucleus to join nervus intermedius at the ventrolateral border of the brain stem. The other follows a lateral course from the superior salivatory nucleus, cutting through the spinal nucleus and tract of the trigeminal nerve to reach the medial border of the vestibular root. This fascicle may join the centrifugal fibers to the inner ear in their course here, or may remain independent as it travels ventralward to join nervus intermedius.

There are two centrifugal bundles to inner ear structures at the lateral border of the medulla in the mouse: a large and a small bundle. The large bundle is the continuation of the visceral efferent system lateral to the superior salivatory nucleus, whereas the small bundle arises particularly from the cells related to the lateral vestibular nucleus. These two fascicles differ not only in size and in origin, but also in position in the vestibular root, in number of collaterals and in termination.

The small bundle enters the central region of the vestibular root and remains somewhat independent in its course, giving off few or no collaterals to either the primary acoustic nuclei or to the large efferent bundle. It terminates in whole or in part in a small plexus of postganglionic neurons and fibers at the ventrolateral edge of the medulla in the superior part of the vestibular ganglion (fig. 5). It receives a few collaterals from the main efferent bundle near its termination (fig. 5). Postganglionics from the neurons of this plexus are extremely difficult to trace, but appear to supply the ampullae of the superior and the Iateral semicircular canals and the macula utriculi. This distribution corresponds to that of the superior ramus of the vestibular nerve in the human.

The large efferent bundle to the inner ear courses lateralward from the superior salivatory nucleus over the dorsal border of the spinal tract of the trigeminal nerve and enters the medial aspect of the vestibular root. This bundle projects collaterals 
into an elongated nucleus (Martin's nucleus) which extends from the base of the restiform body along the medial border of the primary acoustic nuclei (fig. 6). The collaterals ramify greatly in this nucleus and end in knobs, intensely acetylcholinesterase-positive, around the somata of the neurons. Some of the latter cells are slightly acetylcholinesterase-positive, while the majority are not (fig. 7).

The large efferent bundle continues across the vestibular root at the ventral limit of the ventral cochlear nucleus, gives off a few collaterals to the small efferent bundle already described, and penetrates the vestibular ganglion. Some fibers are given off from this bundle in its course through the ganglion but the majority of them run together to the inferior part of the ganglion. The bundle then forks, giving off one branch which curves around the cochlear nerve and is the classical "olviocochlear bundle." while the other branch turns sharply posteriorly toward the saccule and posterior ampulla. As they emerge from the main trunk of fibers, the Schwann and myelin sheaths of these preganglionic fibers begin to stain for butyrylcholinesterase as well as for acetylcholinesterase.

The preganglionic fibers to the saccule terminate among small clusters of postganglionic neurons in the tunica propria of the saccular macula or in similar cells located more proximally along the efferent bundle within the vestibular ganglion. The postganglionic neurons related to the saccule are minimally or moderately acetylcholinesterase-positive and are butyrylcholinesterase-negative. The distribution of their axons corresponds to that of the inferior branch of the vestibular nerve.

The preganglionic fibers to the posterior ampulla end on postganglionic neurons which occur singly or in small ganglia along their course. Many of these postganglionic neurons are minimally acetylcholinesterase-positive, but an occasional cell is highly reactive for the enzyme (fig. 8). No butyrylcholinesterase activity was detected in these postganglionic neurons. Axons of these postganglionic cells distribute with the posterior branch of the vestibular nerve.

The fascicle which forks off from the main efferent bundle and joins the cochlear nerve has the same general pattern of distribution as described for the olivo-cochlear bundle (Rasmussen, '53). The main course of the fascicle is along the cochlear nerve to midmodiolar regions, then upward through the spiral ganglion to the intraganglionic spiral bundle where it bifurcates; one branch turns apicalward and the other, basalward in the intraganglionic spiral bundle. However, individual fibers or small bundles of them leave the large fascicle along its course; these follow two different routes through the cochlea. Some of these fibers wind around the inferior border of the spiral ganglion to reach the root of the osseous spiral lamina where they join the intraganglionic spiral bundle. Others cut through the spiral ganglion to enter the intraganglionic spiral bundle directly.

Postganglionic neurons can be demonstrated histochemically in the intraganglionic spiral bundle of the mouse, which thus corresponds to an autonomic plexus. These postganglionic neurons differ from one another in size, shape, and histochemical reaction (figs, 9-12). Some are small (5-7 $\mu$ ), have eccentric nuclei, rounded contours, and are slightly reactive for acetylcholinesterase (fig. 12). Others are of medium size (around $10 \mu$ ), appear rounded or sometimes bipolar or multipolar and are moderately reactive for the enzyme (figs. 10, 11); still others are large (12$14 \mu$ ), multipolar, and react moderately to heavily for acetylcholinesterase (fig. 9). After counterstaining with cresyl violet an occasional large, multipolar neuron which is not reactive to any extent for acetylcholinesterase, but which receives acetylcholinesterase-positive terminals and gives rise to an axon highly reactive for the enzyme is evident (fig. 10).

Distribution of vestibular postganglionic fibers. Not all of the terminals of the fibers to the vestibular organs have been identified with certainty. Some end in relation to blood vessels, but the latter are not shown well in this type of preparation. However, within each ampulla, some of the fibers turn toward the cells at the base of the crista where they terminate in a network (fig. 13). These cells differ from those of the upper parts of the crista in histochemical reaction, staining positively 
for both acetylcholinesterase and butyrylcholinesterase, whereas the upper cells remain minimally stained or unstained in either substrate. In the macular areas, postganglionic terminals are most conspicuous basally in the epithelium (fig. 14).

Distribution of cochlear postganglionic fibers. Some of the cochlear postganglionic fibers appear to ramify in a vascular plexus at the root of the osseous spiral lamina. Other postganglionic fibers run along the tympanic face of the osseous spiral lamina to its distal border (fig. 15) where some of them bifurcate and may form loops or a plexus. Still other fibers ramify in relation to the axons of bipolar neurons near the foramina nervosa. The peripherally coursing fibers are fine, intensely acetylcholinesterase-positive and unmyelinated.

Orthosympathetic fibers. Acetylcholinesterase-positive fibers turn off from the anterior inferior cerebellar artery to penetrate the cochlear nerve (fig. 16). Such fibers are presumed to be orthosympathetic on the basis of their course along an artery. The fibers run independently of the parasympathetic bundles and of one another through the cochlear nerve. It is impossible to trace them to their termination in the present material as the staining quality of the parasympathetic and of the orthosympathetic fibers is very similar. However, some of the reactive fibers which course individually in the cochlear nerve continue through the spiral ganglion to the intraganglionic bundle. Therefore, the possibility exists that some of the orthosympathetic fibers enter this bundle.

Autonomic fibers related to sensory axons. The distal processes of certain bipolar neurons are acetylcholinesterasepositive in the mouse (figs. 15, 17-19), from approximately the first node distally into the organ of Corti. Some butyrylcholinesterase activity occurs in the glia-myelin sheath of the first internode and around these processes up to the foramen nervosum, but this enzyme is not present distal to the foramen. Some of the positively-reacting distal sensory processes have fine, unmyelinated fibers winding around or running close to them (figs. 17,18 ). In one case such a fine fiber was traced to the region of the foramen nervosum where it thereupon gave rise to three tiny collaterals which terminated in greatly enlarged, acetylcholinesterase-positive knobs upon the distal process of a bipolar neuron (fig. 19). Whether the stem fiber of the terminals was ortho- or parasympathetic could not be conclusively shown with the present technique.

Spiral ganglion. In the species of mouse reported upon here there are some acetylcholinesterase-positive bipolar neurons in the spiral ganglion (fig. 20). These neurons are more numerous basally and in mid-portions of the cochlea than apically. They are located most often at the edge of the spiral ganglion, near the intraganglionic spiral bundle. The cells sometimes possess an eccentric nucleus which is drawn toward the proximal process. Acetylcholinesterase is concentrated at the cell membrane, particularly of the soma, although the proximal portions of both processes of the bipolar neurons are reactive along the axolemma when the $\mathrm{pH}$ of the incubation solutions is high (7.2). The stain occurs cytoplasmically after prolonged incubation times. Neither the cells nor their sheaths stain positively for butyrylcholinesterase, the neurons resembling in this respect the rest of the bipolar neurons of the spiral ganglion. Peripheral processes of some of these neurons enter the intraganglionic spiral bundle.

Efferent fibers frequently appear to form a network around the somata of the acetylcholinesterase-positive bipolar neurons, to coil upon them, or to touch them in passing by (fig. 20). So far, this contact between efferent fibers and bipolar neurons has been observed only in the cochlea, but might also exist in the vestibular areas. Future research must determine whether or not such contact relationships exist between parasympathetic fibers and bipolar neurons, or between acetylcholinesterasepositive orthosympathetic fibers and bipolar neurons.

\section{DISCUSSION}

Centrifugal fibers in the eighth nerve have been described in the literature since the latter part of the nineteenth century (for comprehensive review, see Addens '34; Rasmussen, '46; Rossi and Cortesina, '65a). Many workers thought such fibers 
to be preganglionic salivatory components of nervus intermedius. Since the reports of Papez ('30) and Rasmussen ('46), however, the origin of the centrifugal fibers has been considered to be the superior olivary complex. Both workers made experimental lesions in the region of the superior olivary complex which resulted in degeneration of a bundle which traveled dorsalward, then contralateralward ventral to the facial genu, and across the dorsolateral part of the field to enter the contralateral vestibular nerve. Rasmussen was successful in tracing the bundle into the cochlea and appropriately named it "olivocochlear." Papez thought that the cells of origin for this peduncle were located either in the accessory superior olive, the medial preolivary nucleus, or the nucleus of the trapezoid body. Rasmussen postulated that the cells of origin were in the retro-olivary nucleus and in the medial preolivary nucleus.

Rasmussen ascribed a parasympathetic function to the bundle, basing this hypothesis on the morphology of the predicated cells of origin and on the small size and thin myelinization of the fibers. Later, after the work of Fernandez ('51), Portmann and Portmann ('51), and Portmann ('52), who indicated that the efferent fibers of this bundle reached the inner hair cells of the organ of Corti, Rasmussen ('53) postulated that the bundle might be inhibitory to the hair cells. He found in 1953 that not all of the peripheral fibers of the bundle degenerated when he cut the efferent bundle centrally. He thought the persisting fibers to be axons of bipolar spiral ganglion cells misplaced along the efferent fascicles. Later ('60), he described a homolateral origin for some of the fibers of the bundle. Rasmussen worked on the rat, opossum, dog, cat, and human and found the bundle remarkably similar in all these forms in respect to size, origin, and distribution. Among other workers who have investigated the bundle are Borghesan ('59), Smith and Rasmussen ('63, '65), Gacek, Nomura and Balogh ('65), and Rossi and Cortesina ('63, '65b). Among the authors who have discussed the efferent innervation to the vestibular end organs are Petroff ('55), Rasmussen and Gacek ('58), Gacek ('60), Hilding and Wersäll ('62), Nomura,
Gacek and Balogh ('65), Gacek, Nomura and Balogh ('65), and Rossi and Cortesina ('63, '65b).

Churchill, Schuknecht and Doran ('56) described acetylcholinesterase activity in the centrifugal fiber bundle in the osseous spiral lamina, and in the region of the inner hair cells. Wersäll, Hilding and Lundquist ('61) and Hilding and Wersäll ('62) found acetylcholinesterase activity in the large vesiculated terminals. Vesiculated terminals ending on hair cells of the organ of Corti have been described by Spoendlin ('57), Engström ('58, '60), Smith ('61), Smith and Sjöstrand ('61a, b), Iurato ('62), Hilding and Wersäll ('62), and others.

The findings reported here support Rasmussen's thesis that the bundle he described is parasympathetic, although the cells of origin do not appear to be related to the superior olivary complex in the mouse nor are its fibers centrifugal to the cochlea alone. The cells of origin as determined histochemically are spread over a broad area at the level of the genu of the facial nerve from medially near the raphé to the ventral border of the lataral vestibular nucleus laterally. The cells are subgrouped into three nucei: one medial to the genu; one ventrolateral to the genu; and one at the ventral border of the lateral vestibular nucleus. An additional nucleus of morphologically and histochemically similar cells is located within the borders of the lateral vestibular nucleus. The neurons are typically small to medium-size, multipolar and acetylcholinesterase-positive. The enzyme is cytoplasmically localized, as Gerebtzoff ('59) found to be the case in rabbit preganglionic cells.

Most of the axons of these cells form a common bundle which is partly crossed, (through the decussation ventral to the facial genu), traverses the dorsolateral part of the field and splits into groups of fibers which accompany the vestibular, cochlear, or facial nerves distally. The rest of the axons, few in number, join the facial root in the brain stem. Although the cells of origin of the particular groups of fibers may differ in location, this could not be determined in the present, normal material. It appears that the visceral efferents to the lacrimal and salivary glands and to 
the vestibular and cochlear areas arise from similar regions, share a common decussation, and largely pursue the same course through the brain stem.

Results of much previous work supports the anatomical and histochemical evidence presented here that the system described is broadly distributed and visceral efferent. Van Gehuchten ('27) indicated that the centrifugal fibers to the vestibular root resemble autonomics and arise bilaterally from cells situated medial to the genu of the facial nerve near the midline. Both Kohnstarmm ('02a,b) and Kaida ('29) concluded, on the basis of experimental work, that the preganglionic neurons associated with salivary glands are spread over the wide area defined above. That the cells are chiefly laterally situated, in the superior salivatory nucleus, was indicated by these authors and many others (Yagita and $\mathrm{Ha}$ yama,'09; Yagita, '09; Windle, '33; Addens, '34; and others). The cells clustered around the genu of the facial nerve were described on the basis of histochemical results as salivatory by Lewis and Shute ('59) and Shute and Lewis ('65). Cells dorsal to the facial nucleus (Yagita, '14) or lateral to the genu (Chouard, '62) have been described as lacrimal. The decussation of some of the fibers ventral to the genu has been described by virtually all students of nervus intermedius except for Yagita and Hayama ('09) and Yagita ('09). The central course of visceral efferent fibers through the dorsolateral part of the field and into the vestibular root has been described by Kohnstamm ('02a,b), Van Gehuchten ('27), Kaida ('29), Lorente de Nó ('33) and Addens ('34).

The fact that the central route and decussation of the centrifugal fibers to the vestibular root is, for the most part, the same as that described for a portion of nervus intermedius has been ignored by most students of the olivo-cochlear bundle. The acetylcholinesterase-positive centrifugal fibers to the inner ear should be considered a part of nervus intermedius. This concept has not been suggested in the previous literature, although Windle ('33) actually described the component from the facial root into the vestibular ganglion without naming it; and Van Buskirk ("45) noted that nervus intermedius and the vestibular root intermingle in the dog and human, but not in the cat.

Literature pertaining to the origin of the olivo-cochlear bundle is scarce and findings are not always in agreement. Some support exists for Rasmussen's predication that a portion of the retro-olivary neurons give rise to the crossed olivo-cochlear fascicle (Rossi and Cortesina, '63, '65b; Shute and Lewis, '65). According to the last-quoted authors medial preolivary neurons also contribute to the crossed bundle. Aside from these points of agreement, wide disagreement prevails. Rasmussen's ('46) own retrograde degeneration studies do not support his thesis that the medial preolivary neurons contribute to the crossed olivocochlear bundle, for he found only an occasional atypical cell in this nucleus following section of the decussating fascicle. The direct component to the efferent bundle out of the superior olivary nucleus described by Rasmussen ('60) lacks confirmation. Rossi and Cortesina ('63, '65b) have described four nuclei of origin for the uncrossed centrifugal bundle, which are not in agreement with Rasmussen's results. These nuclei are located as follows: (1) ventralward between the medial and the lateral preolivary nuclei in a region made up of cells morphologically similar to retroolivary neurons; (2) in a reticular nucleus along the dorsal part of the raphé; and (3) and (4) in the lateral part of the dorsal field, with one nucleus lying ventral to and the other within the lateral vestibular nucleus.

Attempts to discover the origin of vestibular efferents experimentally have been similarly fraught with difficulty. Gacek ('60), without anatomical proof, thought the lateral vestibular nucleus to be the source of ipsilateral, centrifugal fibers to the vestibular nerve. In contrast, Carpenter, Bard and Alling ('59) and Carpenter ('60) thought that all of the vestibular nuclei except the lateral gave origin to ipsilateral fibers, while the fastigial nucleus contributed crossed efferent fibers to the peripheral vestibular regions.

The present results do not resolve these discrepancies in the literature. The cells in the superior olivary, in the accessory olivary and in the trapezoid body nuclei, and in Poliak's ('26) and Rasmussen's 
('46) retro-olivary nucleus are not acetylcholinesterase-positive. This agrees essentially with Koelle's ('54) and Gerebtzoff's ('59) findings. The latter author ascribed moderate staining to cells of the rat trapezoid body but the present research indicates that, based on their location and morphology, these cells lie in the lateral preolivary nucleus. This accords well with prior detailed descriptions of this nucleus in the mouse (Cajal, '09; Poliak, '26), the rat (Harrison and Warr, '62), and the cat (Poliak, '26; Taber, '61). The few acetylcholinesterase-positive neurons, located more medially and embedded in trapezoid fibers, are morphologically and histochemically similar to the fusiform neurons of the lateral preolivary nucleus and may be displaced neurons of this nucleus. Cajal ('09) described the medial preolivary nucleus as small and superficial in the mouse, Harrison and Warr ('62) failed to locate it in the rat, and Taber ('61) found it "ambiguous" in the cat. The paucity of acetylcholinesterase-positive cells in the region of the medial preolivary nucleus precludes this nucleus as a primary source of acetylcholinesterase-positive efferent fibers to the inner ear.

Two of the nuclei described by Rossi and Cortesina ('63, '65b) as the origin of vestibular efferents probably correspond to two similarly located nuclei in the mouse: their "interposed" nucleus is comparable in position to the superior salivatory nucleus; the other nucleus lies within the borders of the lateral vestibular nucleus. A third nucleus which they describe as a source of direct reticular fibers to the inner ear is present in the mouse, but no conclusion could be reached concerning its projection. However, by definition, reticular cells are confined to the central nervous system (Rossi and Zanchetti, '57).

Thus, results of the present study do not concur that the centrifugal, acetylcholinesterase-positive fibers to the inner ear arise in the superior olivary complex. It is possible that the olivo-cochlear bundle as described by Rasmussen is not acetylcholinesterase-positive, or that the contribution to this system from the superior olivary complex is small in the mouse and was overlooked.
Connections from the efferent bundle into the ventral cochlear nucleus were described by Rasmussen ('60) for the cat. Comparable relays exist in the mouse, although their distribution is more restricted, the collaterals terminating around the somata of the small cells of Martin's nucleus. Most of these cells are not acetylcholinesterase-positive, so their axons cannot be followed to a termination with the histochemical technique employed. Neither Martin (1894) nor Fuse ('13), who have described this nucleus previously, were successful in learning the distribution of its axons. These cells may be important in regulating acoustic input at the primary nuclei, or in feedback for regulation of parasympathetic outflow to acoustic stimuli.

The peripheral course of the cochlear fascicle to the level of the intraganglionic spiral bundle in the mouse is in close agreement with that originally given by Rasmussen ('46, '53) for the olivo-cochlear bundle in the cat, dog, man, and other forms. New findings are that the parent bundle provides vestibular as well as cochlear efferents and that both sets of efferent fibers terminate, perhaps completely, upon postganglionic neurons scattered along their courses. Within the cochlea, the nurons are all embedded within the fibers of the intraganglionic spiral bundle.

Differences in histochemical reaction which are pronounced between the various postganglionic neurons in the inner ear of the mouse may possibly be related to differences in function. That autonomic cells differ from one another histochemically has been reported previously (Giacobini, '56; Holmstedt, '57; Leaming and Cauna, '61; Cauna et al., '61).

Vestibular postganglionic fibers terminate predominantly among epithelial cells in the maculae and ampullary crests. In the latter case the innervated cells are located at the base of the crista. These cells would appear to be secretory, based upon their histochemical reaction for cholinesterase and their nerve supply, as predicated by Dohlman ('64, '65).

In the cochlea, many postganglionic fibers do not terminate in relation to blood vessels or secretory epithelium. Some of 
these fibers cannot be traced to their termination, but are lost at the distal border of the osseous spiral lamina. Others, which have the same histochemical properties as postganglionic autonomic fibers, form spirals or networks around the somata of the acetylcholinesterase-positive bipolar neurons in the spiral ganglion of the cochlea, some wrap around the distal myelinated processes of bipolar neurons, and some end in knob-like terminals on the unmyelinated segment of the latter neurons proximal to the foramina nervosa (fig. 19). Wolff ('60) has mentioned observing fibers stopping on some vestibular and cochlear bipolar ganglion cells. The fibers described here do not terminate in regions classically considered to be the distribution of the visceral efferent system. These results might suggest that there is a morphological basis for an autonomic modification of sensory input, as some experimental evidence indicates (Seymour and Tappin, '53; Beickert et al., '56; Loewenstein and Altamirano-Orrego, '56; Eldred et al., '60; Hunt, '60; Kimura, '61; Chernetski, '64). They may also provide a morphological basis for the finding that stimulation of the centrifugal bundle to the inner ear in anesthetized animals results in suppression of auditory nerve activity (Galambos, '56) and increased cochlear microphonics (Fex, '59, '62; Desmedt and Monaco, '61).

A possible neurotrophic influence of the parasympathetic system on sensory terminals should be considered. This may be direct or indirect, through regulation of vascular supply or fluid balance. Much excellent research has shown that when the centrifugal fibers to the inner ear are cut centrally (Engström and Fernandez, '61; Iurato, '62; Kimura and Wersäll, '62; Smith and Rasmussen, '63; Spoendlin and Gacek, '63; Spoendlin, '66) or peripherally (Spoendlin and Gacek, '63) the large vesiculated terminals on the hair cells degenerate. Additionally, some investigators have reported that the acetylcholinesterase at the base of the hair cells largely disappears when the centrifugal fibers are cut centrally (Schuknecht, Churchill and Doran, '59; Smith and Rasmussen, '63). These results have been interpreted to prove the physical continuity of the vesiculated ter- minals in the organ of Corti with the axons of cells lying in the medulla when, in fact, they do not. In order to prove this, the entire neuron from its origin to its terminals must be demonstrated; no one has done this. Such studies have shown unequivocally, however, the importance of an intact centrifugal bundle to the well-being of the vesiculated terminals, for if the former is largely or completely destroyed, many or all of the latter will degenerate. The exact reason for the degeneration of the terminals upon removal of the parasympathetic innervation to the inner ear must be found in future research.

Although the present findings indicate that the mouse intraganglionic spiral bundle is largely a parasympathetic plexus, at least two other types of fibers may travel with the bundle. Orthosympathetic fibers appear to enter the bundle, and axons of the acetylcholinesterase-positive bipolar neurons run with it. The latter finding supports results obtained by Lorente de Nó ('37) and Fernandez ('51).

The acetylcholinesterase-positive bipolar neurons are unusual in that they share some of the morphological and histochemical characteristics of both the sensory bipolar neurons and of the autonomic postganglionic cells. They are structurally bipolar neurons and have no butyrylcholinesterase activity, thus resembling the other sensory neurons of the spiral ganglion. However, unlike the sensory neurons, they are acetylcholinesterase-positive (Ross, '66), often possess an eccentric nucleus, are contacted by autonomic fibers, and send their distal processes into the intraganglionic spiral bundle. In these ways, the neurons more closely resemble autonomic cells.

The presence of acetylcholinesterase in the axons of some bipolar neurons proximal to the foramina nervosa in the mouse may be a species variation. Nevertheless, it demonstrates that acetylcholinesterasepositive terminals within the organ of Corti may arise from sensory neurons and are not necessarily efferent. Acetylcholinesterase has been found to occur in sensory terminals elsewhere (Cauna, '61; El Rakhawy and Bourne, '61). Its function in receptors is completely unknown. 


\section{ACKNOWLEDGMENTS}

Animals used in this study were obtained from the Laboratory of Mammalian Genetics through the generosity of Dr. Elizabeth Barto, to whom the author is deeply indebted.

I thank Dr. Rita Ping Liu for her conscientious technique work and for her assistance with photography.

\section{LITERATURE CITED}

Addens, J. L. 1934 A critical review of the occurrence of crossing root-fibers in the facialis, vestibular, glossopharyngeal, and vagus nerves. Psychiat. neurol. Bl. (Amst.), 38: 274-291.

Balogh, K. Jr., and Y. Nomura 1964 A technique for the demonstration of acetylcholinesterase activity in the inner ear after decalcification with EDTA. J. Histochem. Cytochem., 12: 931-933.

Beickert, P., L. Gisselsson and B. Löftström 1956 Der Einfluss des sympathischen Nervensystems auf das Innenohr. Arch. Ohr.-, Nas.-, u. Kehlk.Heilk., 168: 495-507.

Borghesan, E. 1959 On the significance of the intraganglionic spiral bundle. Acta Oto-laryng. (Stockh.), 50: 154-162.

Cajal, S. Ramón y 1909 Histologie du système nerveux de l'homme et des vertébrés. Maloine, Paris.

Carpenter, M. B. 1960 Experimental anatomical-physiological studies of the vestibular nerve and cerebellar connections. In: Neural Mechanisms of the Auditory and Vestibular Systems, edited by G. L. Rasmussen and W. F. Windle. Charles C Thomas, Springfield, Illinois. Chap. XXII, 297-323.

Carpenter, M. B., D. S. Bard and F. A. Alling 1959 Anatomical connections between the fastigial nuclei, the labyrinth and the vestibular nuclei in the cat. J. Comp. Neur., 111: 1-26.

Cauna, N. 1961 Cholinesterase activity in cutaneous receptors of man and some quadrupeds. Histochemistry of Cholinesterase, Symposium Basel 1960. Bibl. anat. (Basel), Fasc., 2: 128138.

Cauna, N., N. T. Naik, D. B. Leaming and P. Alberti 1961 The distribution of cholinesterases in the autonomic ganglia of man and of some mammals. Histochemistry of Cholinesterase, Symposium Basel 1960. Bibl. anat. (Basel), Fasc., 2: 90-96.

Chernetski, K. E, 1964 Sympathetic enhancement of peripheral sensory input in the frog. J. Neurophysiol., 27: 493-515.

Chouard, C. H. 1962 Recherches sur l'organisation intra-axiale des formations motrices et parasympathiques de nerf facial. Private publication.

Churchill, J. A., H. F. Schuknecht and R. Doran 1956 Acetylcholinesterase activity in the cochlea. Laryngoscope, 66: 1-15.

Desmedt, J. E., and P. Monaco 1961 Mode of action of the efferent olivo-cochlear bundle on the inner ear. Nature, 192: 1263-1265.
Dohlman, G. F. 1964 Secretion and absorption of endolymph. Trans. Amer. otol. Soc., 52: 96113.

- 1965 The mechanism of secretion and absorption of endolymph in the vestibular apparatus, Acta Oto-laryng. (Stockh.), 59: 275288.

Eldred, E., H. N. Schnitzlein and J. Buchwald 1960 Response of muscle spindles to stimulation of the sympathetic trunk. Exp. Neurol., 2: $187-195$.

El-Rakhawy, M. T., and G. H. Bourne 1961 Cholinesterases in the human tongue. Histochemistry of Cholinesterase, Symposium Basel 1960. Bibl. anat. (Basel), Fasc., 2: 243-255.

Engström, H. 1958 On the double innervation of the sensory epithelium of the inner ear. Acta Oto-laryng. (Stockh.), 49: 109-118.

1960 Electron micrographic studies of the receptor cells of the organ of Corti. In: Neural Mechanisms of the Auditory and Vestibular Systems, edited by G. L. Rasmussen and W. G. Windle. Charles C Thomas, Springfield, Illinois. Chap. IV, 48-64.

Engström, H., and C. Fernandez 1961 Discussion following a report by Catherine A. Smith. Trans. Amer. otol. Soc., 49: 58-60.

Fernandez, C. 1951 The innervation of the cochlea (Guinea Pig). Laryngoscope, 61: 11521172.

Fex, J. 1959 Augmentation of the cochlear microphonics by stimulation of efferent fibers to cochlea. Acta Oto-laryng. (Stockh.), 50: 540541 .

1962 Auditory activity in centrifugal and centripetal cochlear fibers in cat: A study of feedback system. Acta physiol. scand., 55, (Suppl. 189).

Fuse, G. 1913 Das Ganglion ventrale und das Tuberculum acusticum bei einigen Sảuglingen und beim Menschen. Arb. Hirn-Anat. Inst. Zürich, 7: 1-210.

Gacek, R. R. 1960 Efferent component of the vestibular nerve. In: Neural Mechanisms of the Auditory and Vestibular Systems, edited by G. L. Rasmussen and W. F. Windle. Charles C Thomas, Springfield, Illinois. Chap. XX, 276284.

Gacek, R. R., Y. Nomura and K. Balogh 1965 Acetylcholinesterase activity in the efferent fibers of the stato-acoustic nerve. Acta Otolaryng. (Stockh.), 59: 541-553.

Galambos, R. 1956 Suppression of auditory nerve activity by stimulation of efferent fibers to the cochlea. J. Neurophysiol., 19: 424-437.

Gerebtzoff, M. A. 1959 Cholinesterase (A Histochemical Contribution to the Solution of Some Functional Problems). Pergamon Press, New York.

Giacobini, E. 1956 Histochemical demonstration of acetylcholinesterase activity in isolated nerve cells. Acta physiol. scand. (Suppl. 123124), 36: 276-290.

Harrison, J. M., and B. Warr 1962 A study of the cochlear nuclei and ascending auditory pathways of the medulla. J. Comp. Neur., 119: 341-380.

Hilding, D., and J. Wersäll 1962 Cholinesterase and its relation to the nerve endings in the 
inner ear. Acta Oto-laryng. (Stockh.), 55: 205217.

Holmstedt, B. 1957 A modification of the thiocholine method for the determination of cholinesterase. II. Histochemical application. Acta physiol. scand., 40: 331-337.

Hunt, C. C. 1960 The effect of sympathetic stimulation on mammalian muscle spindles. J. Physiol. (Lond.), 151: 332-341.

Iurato, S. 1962 Efferent fibers to the sensory cells of Corti's organ. Exp. Cell Res., 27: 162164.

Kaida, Y. 1929 Uber den Ursprung und den peripheren Verlauf der sog. zentrifugalen Vestibularisnerven nach Leidler (Fasciculus vestibularis medialis nach Kaplan). Arch. Ohr.-, Nas.-, u. Kehlk.-Heilk., 123: 62-69.

Kimura, K. 1961 Factors affecting the response of taste receptors of rat. Kumamoto med. J., 14: 95-99.

Kimura, R. and J. Wersäll 1962 Termination of the olivo-cochlear bundle in relation to the outer hair cells of the organ of Corti in guinea pig. Acta Oto-laryng. (Stockh.), 55: 11-32.

Koelle, G. B. 1954 The histochemical localization of cholinesterase in the central nervous system of the rat. J. Comp. Neur., 100: 211235.

Kohnstamm, O. 1902a Vom Centrum der Speichelsekretion, dem Nervus intermedius und der gekreuzten Facialiswurzel. Verh. dtsch. Kongr. inn. Med., 20: 361-373.

$1902 \mathrm{~b}$ Der Nucleus salivatorius chordae tympani (Nervi intermidii). Anat. Anz., 21: 362-363.

Leaming, D. B., and N. Cauna 1961 A qualitative and quantitative study of the myenteric plexus of the small intestine of the cat. J. Anat. (Lond.), 95: 160-169.

Lewis, P. R., and C. C. D. Shute 1959 Selective staining of visceral efferents in the rat brain stem by a modified Koelle technique. Nature, 183: 1743-1744.

Lorente de Nó, R. 1933 Anatomy of the eighth nerve. Laryngoscope, 43: 1-38.

1937 Symposium: The neural mechanisms of hearing: I. Anatomy and physiology (b). The sensory endings in the cochlea. Laryngoscope, 47: 373-377.

Loewenstein, W. R., and R. Altamirano-Orrego 1956 Enhancement of activity in a Pacinian corpuscle by sympathomimetic agents. Nature (Lond.), 178: 1291-1293.

Martin, P. 1894 Zur Endigung des Nervus acusticus im Gehirn der Katze. Anat. Anz., 9: 181-184.

Nomura, Y., R. R. Gacek and K. Balogh 1965 Efferent innervation of vestibular labyrinth: Histochemical demonstration of acetylcholinesterase activity in the guinea pig inner ear. Arch. Otolaryng., 81: 335-339.

Papez, J. W. 1930 Superior olivary nucleus-its fiber connections. Arch. Neurol. Psychiat., 24: $1-20$.

Petroff, A. E. 1955 An experimental investigation of the origin of efferent fiber projections to the vestibular neuroepithelium. Anat. Rec., 121: 352-353.
Poliak, S. 1926 Untersuchungen am Oktavussystem der Säugetiere und an den mit diesem koordinierten motorischen Apparaten des Hirnstammes. Eine morphologisch-biologische Studie. J. Psychol. Neurol. (Lpz.), 32: 170-231.

Portmann, M. 1952 Les fibres nerveuses efférentes cochléaires. Thesis. Imprimerie-Librairie Delmas, 6, place Saint-Christoly, Bordeaux.

Portmann, M., and C. Portmannn 1951 Les fibres spirales de la cochlée. Rev. Laryng., 72 . $737-750$.

Rasmussen, G. L. 1946 The olivary peduncle and other fiber projections of the superior olivary complex. J. Comp. Neur., 84: 141-219. 1953 Further observations of the efferent cochlear bundle. J. Comp. Neur., 99: 61-74.

1960 Efferent fibers of the cochlear nerve and cochlear nucleus, In: Neural Mechanisms of the Auditory and Vestibular Systems, edited by G. L. Rasmussen and W. F. Windle. Charles C Thomas, Springfield, Illinois. Chap. VIII, 105-115.

Rasmussen, G. L., and R. R. Gacek 1958 Concerning the question of an efferent fiber component of the vestibular nerve of the cat. Anat. Rec., 130: 361-368.

Ross, M. D. 1965a A comparison of the normal cochlea with the abnormal of the waltzing mouse. (Abstract). Anat. Rec., 151: 408.

$1965 \mathrm{~b}$ The auditory pathway of the epileptic waltzing mouse. II. Partially deaf mice, J. Comp. Neur., 125: 141-164.

1966 Cholinesterase activity in the auditory pathway in normal and abnormal mice. (Abstract). Anat. Rec., 154: 414.

Rossi, G., and G. Cortesina 1963 Research on the efferent innervation of the inner ear. J. Laryng., 77: 202-233.

1965a The efferent innervation of the inner ear. A historical-bibliographical survey. Laryngoscope, 75: 212-235.

1965b The "efferent cochlear and vestibular system" in Lepus cuniculus L. Acta anat. (Basel), 60: 362-381.

Rossi, G. F., and A. Zanchetti 1957 The brain stem reticular formation: Anatomy and physiology. Arch, ital. Biol., 95: 199-435.

Schuknecht, H. F., J. A. Churchill and R. Doran 1959 The localization of acetylcholinesterase in the cochlea. Arch. Otolaryng., 69: 549-559.

Seymour, J. C., and J. W. Tappin 1953 Some aspects of the sympathetic nervous system in relation to the inner ear. Acta Oto-laryng. (Stockh.), 43: 618-635.

Shute, C. C. D., and P. R. Lewis 1965 Cholinesterase-containing pathways of the hindbrain: Afferent cerebellar and centrifugal cochlear fibers. Nature, 205: 242-246.

Smith, C. A. 1961 Innervation pattern of the cochlea - the internal hair cell. Trans. Amer. otol. Soc., 49: 35-60.

Smith, C. A., and G. L. Rasmussen 1963 Recent observations on the olivo-cochlear bundle. Ann. Otol. (St. Louis), 72: 489-506.

1965 Degeneration in the efferent nerve endings in the cochlea after axonal section. J. Cell Biol., 26: 63-76. 
Smith, C. A., and F. S. Sjöstrand 1961a A synaptic structure in the hair cells of the guinea pig cochlea. J. Ultrastruct. Res., 5: 184-192.

$1961 \mathrm{~b}$ Structure of the nerve endings on the external hair cells of the guinea pig cochlea as studied by serial sections. J. Ultrastruct. Res., 5: 523-556.

Spoendlin, H. H. 1957 Elektronenmikroskopische Untersuchungen am Cortischen Organ des Meerschweinchens. Pract. oto-rhino-laryng. (Basel), 19: 192-234.

1966 The Organization of the Cochlear Receptor, edited by Prof. Dr. L. Rüedi, Basel (Switzerland), S. Karger/New York.

Spoendlin, H. H., and R. R. Gacek 1963 Electron microscopic study of the efferent and afferent innervation of the organ of Corti in the cat. Ann. Otol. (St. Louis), 72: 660-686.

Taber, E. 1961 The cytoarchitecture of the brain stem of the cat. I. Brain stem nuclei of cat. J. Comp. Neur., 116: 27-69.

Van Buskirk, C. 1945 The seventh nerve complex. J. Comp. Neur., 82: 303-335.

Van Gehuchten, P. 1927 Recherches expérimentales pur les terminaisons du nerf vesti- bulaire et sur les voies vestibulaires centrales. Rev. Oto-neuro-oculistique, 5: 777-791.

Wersäll, J., D. Hilding and P. G. Lundquist 1961 Ultrastruktur und Innervation der Cochleären Haarzellen. Arch. Ohr.-, Nas.-, u. Kehlk.-Heilk., 178: 106-126.

Windle, W. F. 1933 Neurofibrillar development in the central nervous system of cat embryos between 8 and $12 \mathrm{~mm}$ long. J. Comp. Neur., 58: $643-723$.

Wolff, D. 1960 Discussion of neural mechanisms in the vestibular system. In: Neural Mechanisms of the Auditory and Vestibular Systems, edited by G. L. Rasmussen and W. F. Windle. Charles C Thomas, Springfield, Illinois. Chap. XXIV: 359-361.

Yagita, K. 1909 Weitere Untersuchungen über das Speichelzentrum. Anat. Anz., 35: 70-75.

- 1914 Einige Experimente an dem Nervus petrosus superficialis major zur Bestimmung des Ursprungsgebietes des Nerven. Folia neuro-biol. (Lpz.), Bd. VIII: 361-382.

Yagita, K., and S. Hayama 1909 t'ber das Speichelsekretionscentrum. Neurol. Centralbl., Bd., 28: 738-753.

\section{Abbreviations}

AIC, Anterior inferior cerebellar artery $B$, Cells at the base of the crista ampullaris BP, Bipolar neuron distal process

$\mathrm{CA}$, Crista ampullaris

$\mathrm{CN}$, Cochlear nerve

DR, Distal portion of facial root

EF, Efferent visceral fascicle

F, Facial nucleus

FN, Foramen nervosum

$G$, Genu of facial nerve

IG, Intraganglionic spiral bundle

LB, Looping visceral efferent bundle
MB, Main visceral efferent bundle

MS, Macula sacculi

PG, Preganglionic cells

PGC, Postganglionic cells

RC, Reticular cells

S, Superior salivatory nucleus

SG, Spiral ganglion

SL, Spiral limbus

SO, Superior olivary nucleus

VCN, Ventral cochlear nucleus

VE, Visceral efferent ("olivo-cochlear") bundle

VG, Vestibular ganglion

PLATE 1

EXPLANATION OF FIGURES

1 The laterally coursing visceral efferent bundle ("olivo-cochlear") is shown here (VE). There is no discrete, stained fascicle out of the superior olivary complex. DR, distal portion of the root of the facial nerve; G, genu of the facial nerve; LB, looping visceral efferent bundle into the region of the lateral vestibular nucleus; $S$, superior salivatory nucleus; SO, superior olivary nucleus. $\mathrm{pH} 6.8$. $\times 45$.

2 The most caudal neurons of the lateral preolivary nucleus (heavy arrow) send their dorsal processes into the facial nucleus (F). SO, superior olivary nucleus. $\mathrm{pH}$ 6.0. Counterstained with cresyl violet. $\times 275$. 

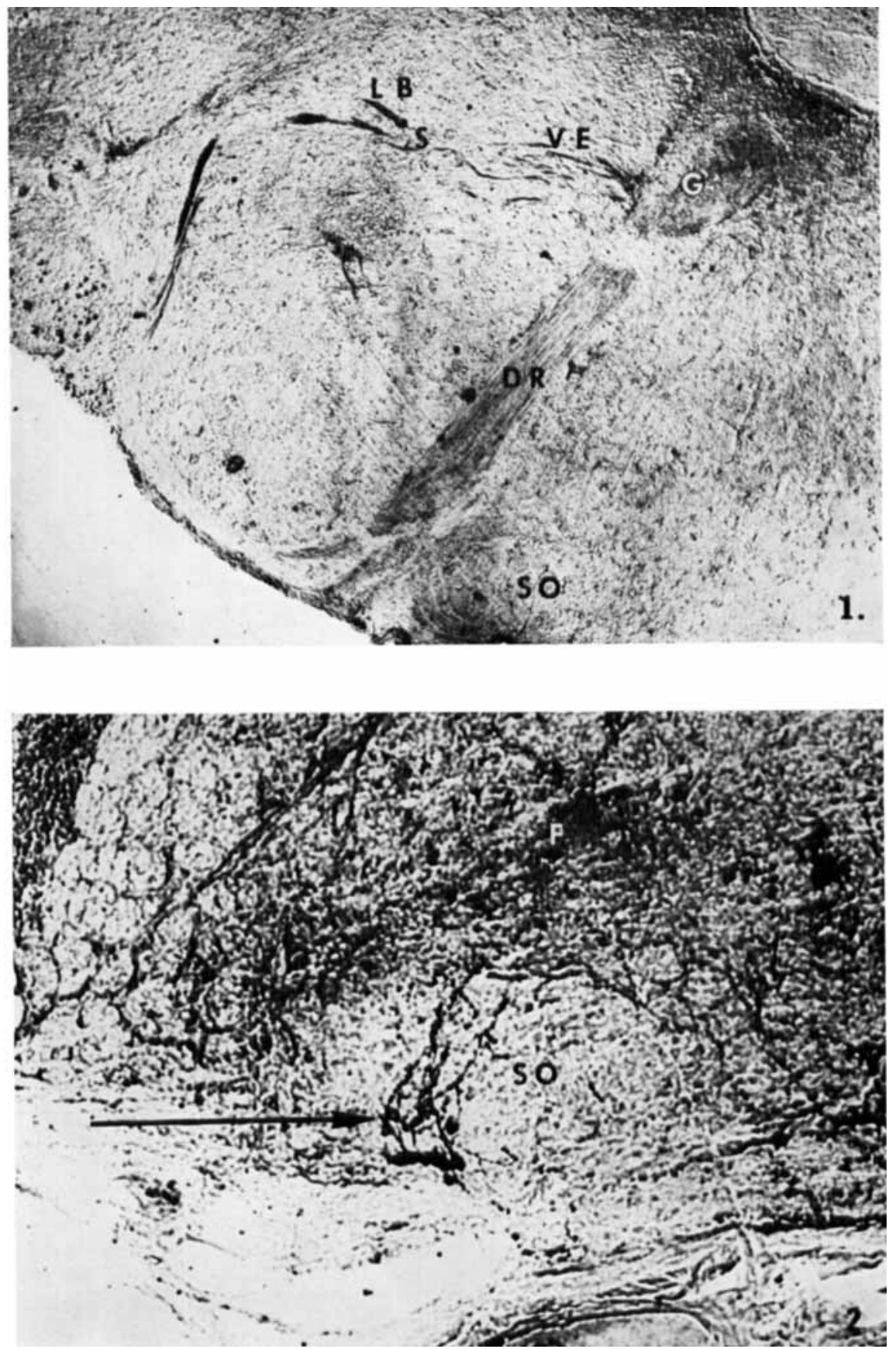


\section{PLATE 2}

EXPLANATION OF FIGURES

3 There is a small nucleus lateral to the genu (G) of the facial nerve which gives origin to a part of the efferent fascicle to the inner ear. PG, preganglionic neurons; $R C$, reticular cells; VE, visceral efferent bundle. The rounded black structures are air-bubble artifacts, pH 6.8 . $\times 125$.

4 Some of the fibers crossing the midline turn into the genu (G) or distal portion of the root (DR) of the facial nerve (slender arrows); others hook under the genu (heavy arrow) to join the laterally directed visceral efferent bundle. pH 6.4. $\times 150$. 

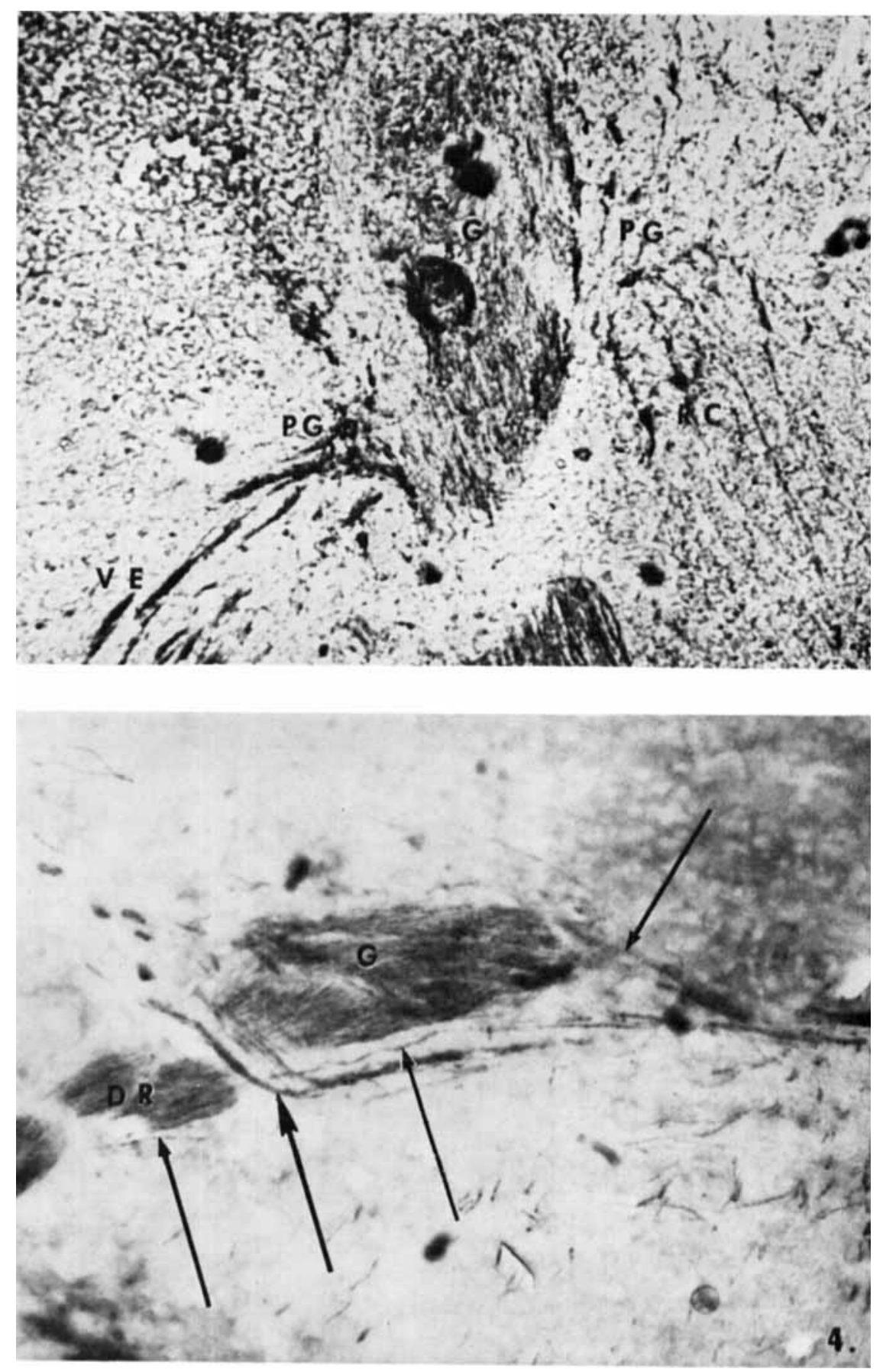
PLATE 3

\section{EXPLANATION OF FIGURES}

5 A small nucleus of postganglionic cells (PGC) is located at the tip of the ventral cochlear nucleus (VCN) in the vestibular ganglion (VG). Slender collaterals (arrow) from the main visceral efferent bundle (MB) to the inner ear project into this region. $\mathrm{pH}$ 6.0. Counterstained with cresyl violet. $\times 200$.

6 Slender collaterals (fine arrows) of the main efferent bundle (MB) to the inner ear enter the basal cells of the ventral cochlear nucleus (VCN). The pale staining fascicle indicated by the heavy arrow is part of nervus intermedius. pH 6.4. $\times 125$.

7 The basal cells of the ventral cochlear nucleus are, for the most part, acetylcholinesterase-negative (heavy arrows). The fine arrow indicates a collateral from the visceral efferent system which ramifies in the region. $\mathrm{pH} 6.4 . \times 1500$.

8 An acetylcholinesterase-positive postganglionic neuron (arrow) is shown along the course of the efferent fascicle (EF) to the posterior ampulla. pH 6.4. $\times 2000$. 

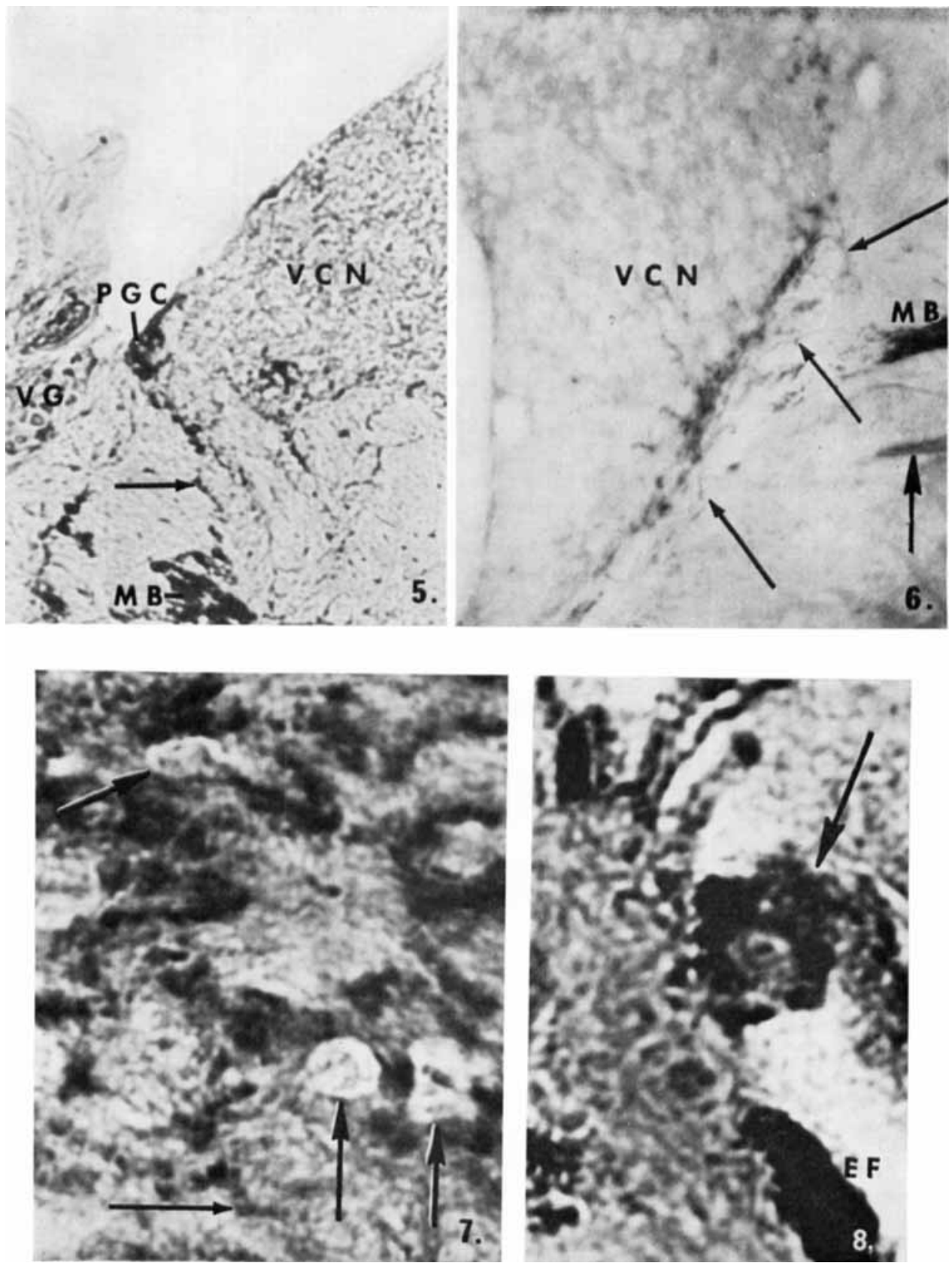
PLATE 4

EXPLANATION OF FIGURES

9 Two acetylcholinesterase-positive postganglionic cells in the intraganglionic spiral bundle are indicated by heavy arrows. They have numerous, positively reacting terminals on their somata; two of these terminals are indicated by slender arrows. pH 6.4. $\times 1600$.

10 Three types of postganglionic cells lie side by side in the intraganglionic bunde in this section. The arrow (1) indicates a highly reactive cell; the arrow (2) indicates the axon hillock of a neuron mildly reactive for acetylcholinesterase which has a heavily stained axon; the double arrows indicate a cell of intermediate staining quality which has a markedly eccentric nucleus. $\mathrm{pH}$ 6.0. Counterstained with cresyl violet. $\times 1500$.

11 An acetylcholinesterase-positive postganglionic neuron of intermediate size is shown in the intraganglionic spiral bundle. This cell has a few prominent acetylcholinesterase-positive synapses, one of which is indicated by an arrow. pH 6.4. Whole head pretreated with EDTA. $\times 1700$.

12 Two small postganglionic neurons with little or no enzymatic reaction located in the intraganglionic spiral bundle are shown here, $\mathrm{pH}$ 6.4. Whole head pretreated with EDTA. $\times 2000$.

13 Cells at the base (B) of the crista ampullaris (CA) are cholinesterasepositive. They are innervated basally by a network of autonomic fibers (arows). pH 6.4. $\times 375$. 

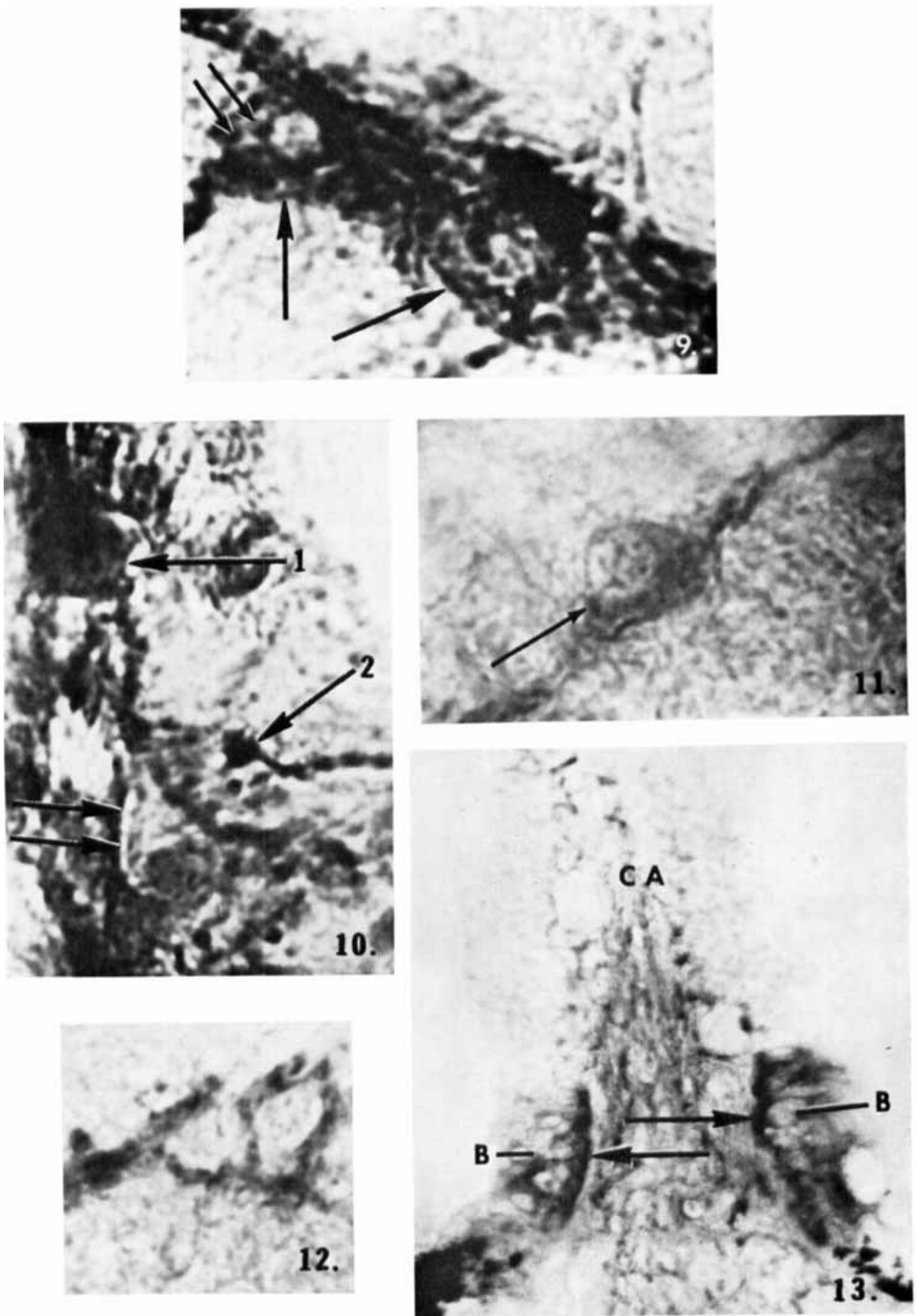
PLATE 5

EXPLANATION OF FIGURES

14 The macula sacculi (MS) is innervated basally by efferent fibers, indicated by arrows. $\mathrm{pH}$ 6.4. $\times 150$.

15 The fibers coursing out of the intraganglionic spiral bundle (IG) run along the tympanic border of the osseous spiral lamina (arrow 1 ). The terminal portions of some of the bipolar neurons are acetylcholinesterase-positive (arrows 2 and 3 ). FN, foramen nervosum; SL, spiral limbus. pH 6.4. $\times 500$. 

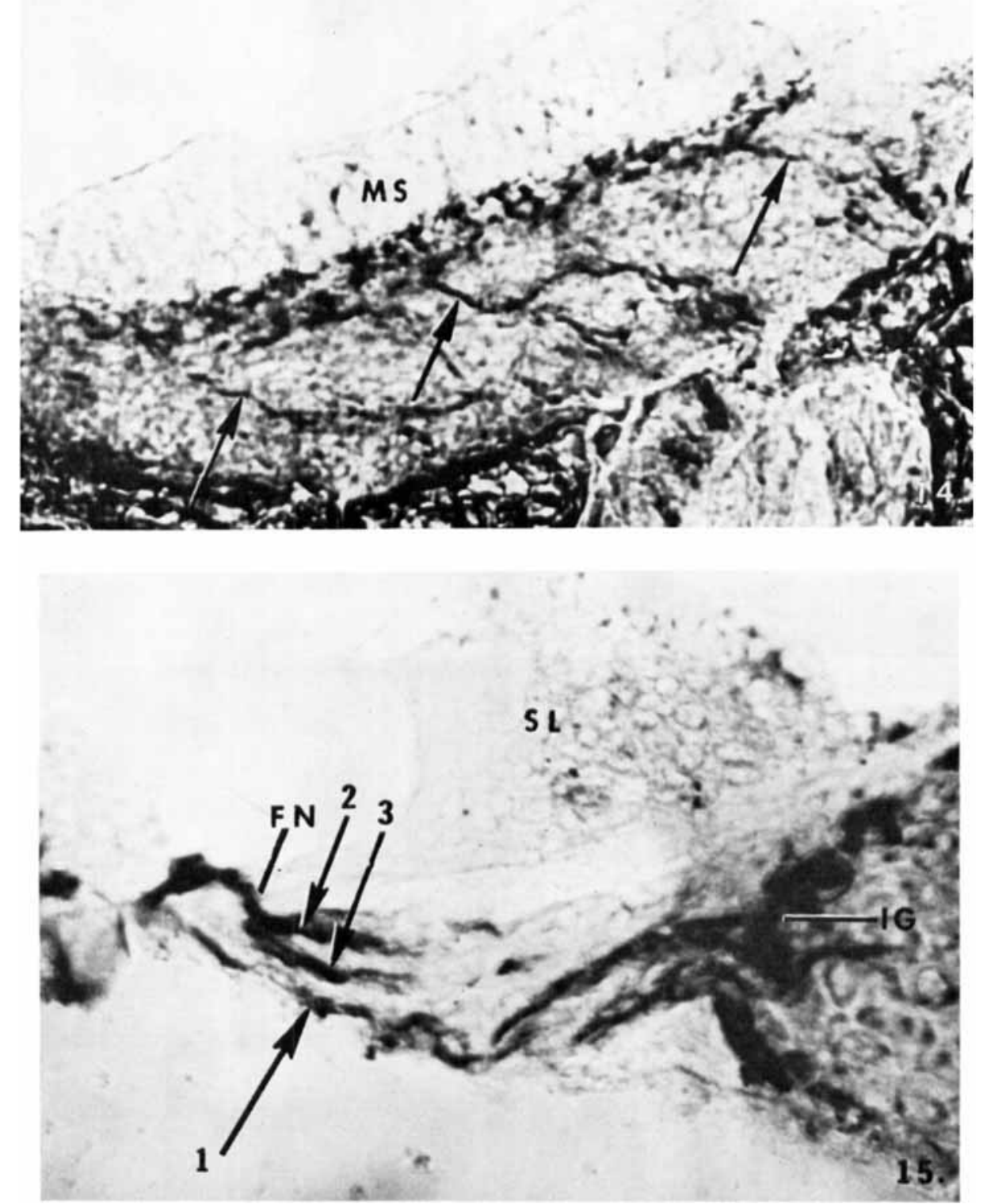
PLATE 6

EXPLANATION OF FIgURES

16 Orthosympathetic fibers, two of which are indicated by arrows, join the cochlear nerve (CN) from the anterior inferior cerebellar artery (AIC). Many more such fibers are shown in the field. pH 5.5. Counterstained with cresyl violet. $\times 500$.

17 A Schwann cell nucleus is indicated by a heavy arrow. An unmyelinated fiber (slender arrow) runs toward the distal process of a bipolar neuron (BP). FN, foramen nervosum. $\mathrm{pH} 6.4$. $\times 200$.

18 A fine fiber, indicated by a heavy arrow, runs toward the distal myelinated segments of bipolar neurons (BP) where it appears to end. pH 6.4. $\times 2000$. 


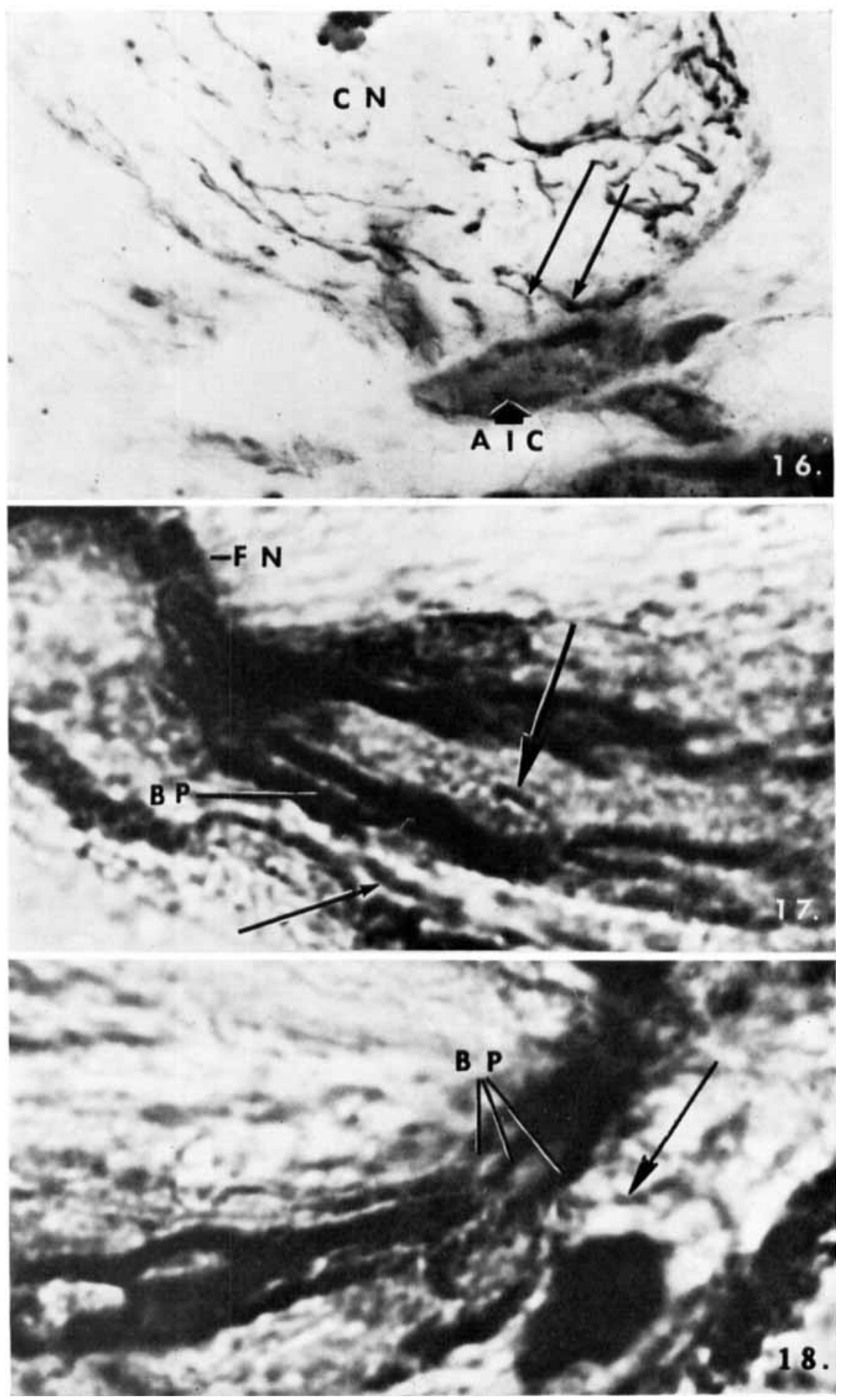


PLATE 7

EXPLANATION OF FIGURES

19 A fine, acetylcholinesterase-positive fiber (arrow 1) runs toward the foramen nervosum (FN). Near the foramen it branches (arrow 2) into three terminals, two of which are shown here. An end knob of one of the terminals on the axon of a bipolar neuron at the foramen nervosum is indicated by arrow 3. pH 5.5. Counterstained with cresyl violet. $\times 200$.

20 Acetylcholinesterase-positive fibers coil about some positively reacting bipolar neurons (arrows). The somata of other bipolar neurons can be seen in the background. IG, intraganglionic spiral bundle; SG, spiral ganglion, $\mathrm{pH} 5.5$. Counterstained with cresyl violet. $\times 1100$. 

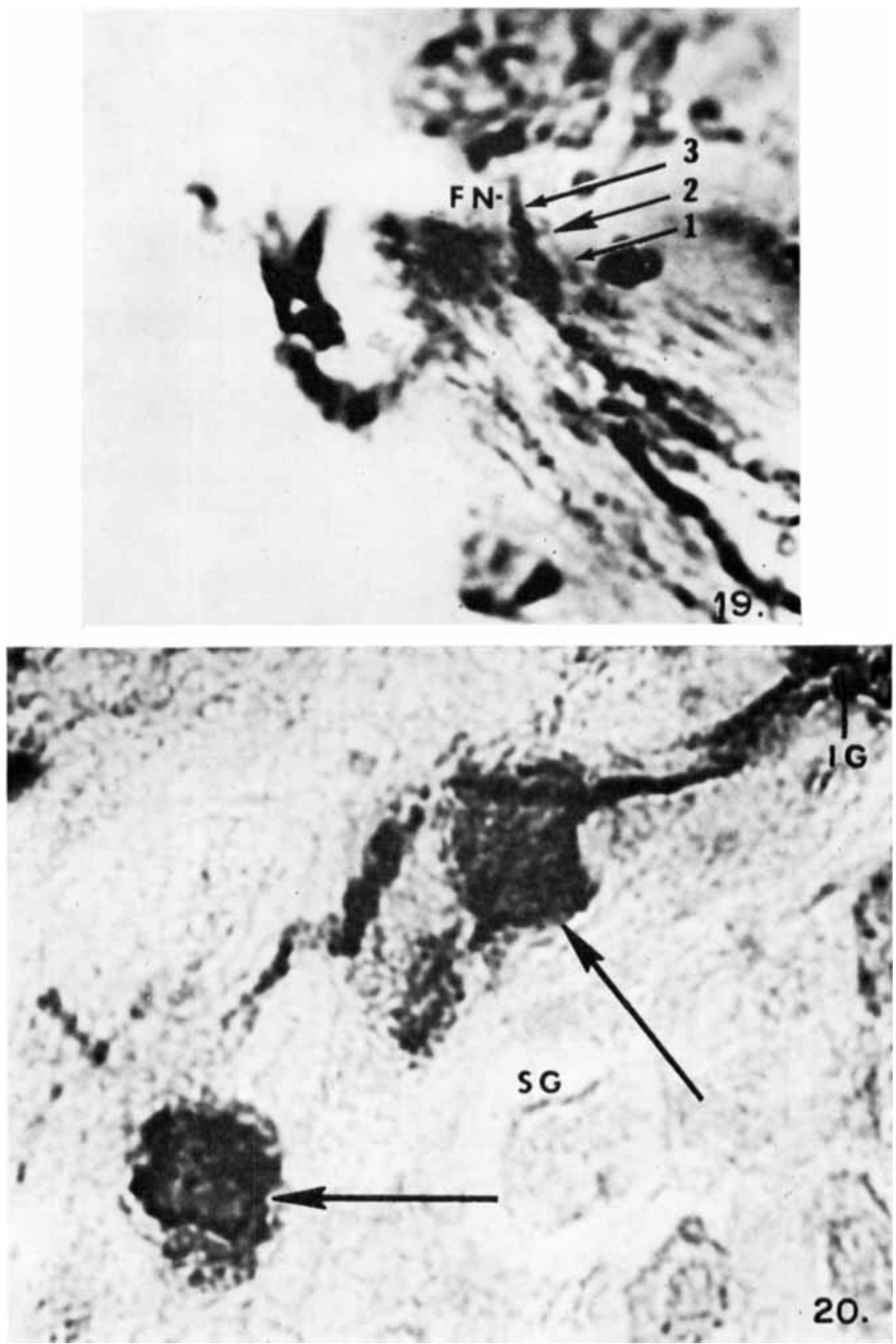